\title{
Efficient Gene Transfer to Human Endothelial Cells Using DNA Complexed to Adenovirus Particles
}

BioTechniques 25:264-272 (August 1998)

Cora-Jean S. Edgell, David T. Curiel ${ }^{1}$, Ping-Chuan Hu and Henry S. Marr

University of North Carolina, Chapel Hill, NC; ${ }^{1}$ University of Alabama, Birmingham, AL, USA

\section{INTRODUCTION}

Human endothelial cells are reportedly difficult to transfect $(17,21)$. For this reason, the mechanisms of endothelium-specific gene expression have been difficult to study (11). The level of transfected reporter gene expression in human umbilical vein endothelial cells (HUVECs) has been reported to be less than $1 \%$ of that in HeLa cells (26). In a recent study, 5 different transfection methods were optimized for early-passage HUVECs, including electroporation, lipofection, transferrinfection, DEAE-dextran transfection and calcium phosphate transfection (23). The best HUVEC transfection rate achieved was $0.68 \%$ of the population. In the same study, the continuous human endothelium-derived EA.hy926 cell line (7), which maintains an extensively differentiated phenotype (20), was also found to be refractory to transfection, despite its vigorous growth properties. After optimization of 5 transfection methods for EA.hy926 cells, Teifel et al. (23) found that the best transfection efficiency achieved was $2 \%$.

Because endothelial cells serve many important physiological transport functions involving specialized intra- cellular pathways, incoming macromolecules that do not trigger a specific pathway can be efficiently diverted to lysosomes for degradation. This could explain why endothelial cells are relatively refractory to most methods of transfection. However, DNA incorporated into viruses can avoid lysosomal degradation because viral coat proteins trigger the disruption of endosomes before they combine with lysosomes (22). Retroviruses and adenoviruses have been used to transfer DNA sequences that have been incorporated into the viral genome into many cell types including endothelial cells $(8,13,27)$. However, this approach limits the size of the DNA that can be transferred because it must be packaged within the virus. Furthermore, nucleic acid constructions, viral packaging, amplification in a producer cell type (that might be sensitive to the transgene), purification and titration must be accomplished before transfer to the recipient cell of interest. In addition, it is less feasible to analyze DNA sequences for promoter functions after incorporation into viral genomes because of potential cis interactions with viral regulatory elements.

These major limitations of virusmediated transfection can be avoided. It has been demonstrated that DNA that is 
not incorporated into the viral genome can nevertheless be transfected into cultured cells relatively efficiently if adenovirus particles are present during exposure of the cells to the DNA $(4,9,19)$. DNA segments of up to $48 \mathrm{~kb}$ can be transfected into cells in this way (3). Reporter signals have been shown to increase manyfold when the virus particles are actually complexed with the DNA being transfected. Complexing the negatively charged DNA to adenovirus using polylysine that has been enzymatically conjugated to the virus has been effective in transfection of mouse hepatocytes (24). Adenovirus has also been shown to be effective in conjunction with DEAE-dextran in enhancing transfection of $\mathrm{CHO}$, rat-1 fibroblasts and primary rat osteoblasts (9). Positively charged DEAE-dextran can link negatively charged DNA and virus particles and promote their attachment to negatively charged cell surfaces as well as promote endocytosis. Adenovirus added to plasmid DNA in the presence of LIPOFECTAMINETM (Life Technologies, Gaithersburg, MD, USA) has been shown to cause the DNA to be incorporated into large electrophoretically stable complexes and to enhance bovine aortic endothelial cell transfection by orders of magnitude compared to DNA with just LIPOFECTAMINE (19). Virus-specific antibody conjugated to positively charged polylysine has also been used to complex the adenovirus to DNA and shown to be effective in enhancing the transfection of $\mathrm{CHO}$ cells (5).

This report demonstrates that differentiated human endothelial cells can be efficiently transfected by complexing the transfecting DNA with adenovirus particles. The relative contributions of the virus component and of the antibody-polylysine complexing reagent to the reporter signal obtained are determined. A linear relationship between DNA concentrations and the transfection signal is demonstrated in the clonally pure EA.hy926 endothelial cells. Early-passage HUVECs and cells of the continuous EA.hy926 line are transfected at similar frequencies. Efficient transfection was accomplished using this method even though human endothelial cells are relatively refractory to other methods of transfection.

\section{MATERIALS AND METHODS}

\section{Cells}

HUVECs were isolated as described by Jaffe et al. (12) and Gimbrone (10) and cultured on gelatin-coated tissue culture plasticware in $\mathrm{EGM}^{\circledR}{ }^{\circledR} \mathrm{UV}$ with bovine brain extract (BBE) (Clonetics, San Diego, CA, USA) supplemented with $12 \%$ fetal bovine serum (FBS). The cells were positive for von Willebrand antigen (an endothelial cell marker) as determined after the first subpassage using a previously described immunofluorescence assay (7). The HUVECs were used in these experiments prior to 10 population doublings in culture. The A549/8 cell line (1) is a relatively undifferentiated hypoxanthine guanine phosphoribosyltransferase-deficient derivative of the human lung carcinoma cell line A549 (14). The EA.hy926 cell line (7) is a continuous differentiated endothelial cell line derived by hybridization of an HUVEC with an A549/8 cell. EA.hy926 cells were cultured in Dulbecco's modified Eagle medium (DMEM) with high glucose, supplemented with $10 \%$ FBS, plus HAT (100 $\mu \mathrm{M}$ hypoxanthine, 0.4 $\mu \mathrm{M}$ aminopterin, $16 \mu \mathrm{M}$ thymidine) and antibiotics. A549/8 cells were cultured under the same conditions except that the medium was supplemented with $100 \mu \mathrm{M}$ 6-thioguanine instead of HAT.

\section{Reporter DNAs}

The luciferase reporter construct pCLuc4 contains the Photinus pyralis luciferase cDNA downstream of the cytomegalovirus (CMV) early promoter/ enhancer (18). The $\beta$-galactosidase reporter construct $\mathrm{pCMV} \beta$ contains the Escherichia coli lacZ gene downstream of the CMV immediate early enhancer promoter (15). The plasmid pCLuc4 DNA was purified by cesium chloride banding, and the pCMV $\beta$ DNA was purified by passage through a pZ523 ${ }^{\mathrm{TM}}$ column (5 Prime $\rightarrow 3$ Prime, Boulder, CO, USA).

\section{Adenovirus}

Two types of adenovirus were used in this work: (i) P202-Ad5, which is replication-competent, and (ii) P259-
Ad5, which is derived from P202-Ad5 by deleting the E1A/E1B gene region to make it replication-incompetent (5). Because E1A and E1B are the first genes expressed by adenovirus, on which all other viral gene expression is dependent, no effect of the viral genome is expected in transfectants involving $\mathrm{P} 259-\mathrm{Ad} 5$. Both these viruses include a useful heterologous epitope in the surface region of the viral hexon protein, which has no effect on infectivity (5).

\section{Antibody}

The mouse monoclonal antibody MP301 (5) is specific for a heterologous epitope expressed at the surface of the adenovirus strains P202-Ad5 and P259-Ad5. The antibody was purified from ascites fluid by protein A affinity.

\section{Transfection Complex Formation}

In advance, poly(L-lysine) with an average polymer length of 300 residues was conjugated at equal molar ratios to MP301 antibody and separately to transferrin as previously described (2,5, 25 ) and stored at $-20^{\circ} \mathrm{C}$. Transfection complexes were prepared immediately before use in HEPES-buffered saline (HBS) (20 mM HEPES, pH 7.3 with $150 \mathrm{mM} \mathrm{NaCl}$ ). For each $\mathrm{cm}^{2}$ of culture to be transfected, $1.25 \times 10^{9}$ adenovirus particles were combined with $100 \mathrm{ng}$ antibody-poly(L-lysine) in $\mathbf{1 2 . 5}$ $\mu \mathrm{L}$ HBS and incubated for $30 \mathrm{~min}$ at room temperature. Then, $300 \mathrm{ng}$ of plasmid DNA in $6.25 \mu \mathrm{L}$ HBS were added and incubated for $30 \mathrm{~min}$ at room temperature. Finally, $300 \mathrm{ng}$ of transferrin-poly(L-lysine) in $6.25 \mu \mathrm{L}$ HBS were added and incubated for another $30 \mathrm{~min}$ at room temperature. For one experiment, $2 \%$ (vol/vol) FBS was added to the transfection complex preparation just before it was applied to cell cultures.

\section{Transfection Protocol}

Replicate cultures were plated 2 days before transfection experiments at densities that would be subconfluent at the time of transfection. Just before adding the transfection complex, cultures were rinsed in culture medium with $10 \mathrm{mM}$ HEPES (pH 7.3) and 2\% 
FBS. For each $\mathrm{cm}^{2}$ of culture, $25 \mu \mathrm{L}$ of transfection complex were added, and the cultures were left at room temperature for $1 \mathrm{~h}$. Then an equal volume of culture medium containing 2\% FBS and $10 \mathrm{mM}$ HEPES ( $\mathrm{pH}$ 7.3) was added, and the culture incubated for another hour at room temperature, after which the usual volume of complete culture medium was added, and the culture was returned to the $37^{\circ} \mathrm{C} \mathrm{CO}_{2}$ incubator.

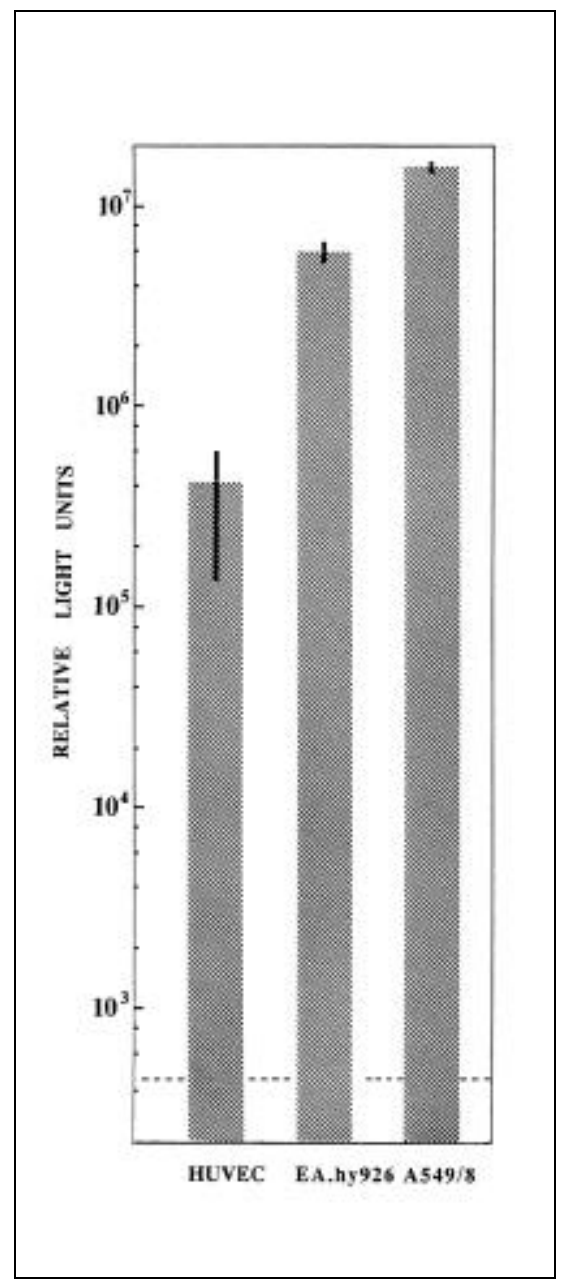

Figure 1. Transfection reporter signals obtained with cultures of differentiated human endothelium-derived and related cells. Cultures of HUVECs, EA.hy926 cells and A549/8 cells were transfected with $300 \mathrm{ng} / \mathrm{cm}^{2}$ pCLuc4 DNA complexed with replication-defective adenovirus P259A and transferrin-polylysine as described. The cells were extracted after $24 \mathrm{~h}$, and samples representing $2 \mathrm{~cm}^{2}$ of culture were assayed for luciferase activity. For each cell type, the mean number of light units produced by three replicate cultures and the range are displayed. The dashed line indicates the assay background with no cellular extract.

\section{Reporter Gene Assays}

The assay used for luciferase is based on that of de Wet et al. (6). One day after transfection, cultures were rinsed well with phosphate-buffered saline and then lysed in luciferase extraction buffer $\left(1 \%\right.$ Triton ${ }^{\circledR} \mathrm{X}-100,25$ $\mathrm{mM}$ glycylglycine, $\mathrm{pH} 7.8,15 \mathrm{mM}$ $\mathrm{MgSO}_{4}, 4 \mathrm{mM}$ EGTA, $1 \mathrm{mM}$ dithiothreitol [DTT]) using $50 \mu \mathrm{L} / \mathrm{cm}^{2}$ of culture. The extracts were cleared of cellular debris by brief centrifugation and stored at $-20^{\circ} \mathrm{C}$ until assayed. For each assay, up to $100 \mu \mathrm{L}$ of cytoplasmic extract were added to $400 \mu \mathrm{L}$ luciferase assay buffer $(25 \mathrm{mM}$ glycylglycine, $\mathrm{pH}$ 7.8, $15 \mathrm{mM} \mathrm{MgSO}_{4}, 4 \mathrm{mM}$ EGTA, 15 $\mathrm{mM} \mathrm{KHPO}$, $1 \mathrm{mM}$ DTT, $2 \mathrm{mM}$ ATP). Then $100 \mu \mathrm{L}$ of substrate solution $(0.2$ $\mathrm{mM}$ D-luciferin, $25 \mathrm{mM}$ glycylglycine, $\mathrm{pH} 7.8,15 \mathrm{mM} \mathrm{MgSO}$, 2 mM DTT)

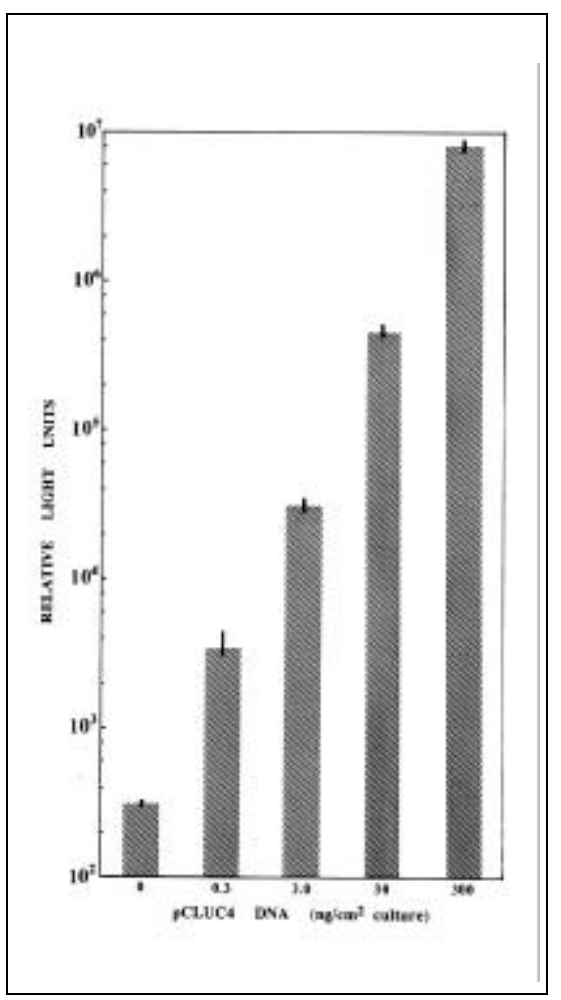

Figure 2. Linear relationship between the amount of DNA transfected and the reporter signal from EA.hy926 cells. Subconfluent cultures were transfected with various amounts of pCLuc4 DNA complexed with the usual amount of adenovirus P202 and transferrin-polylysine as described. The cells were extracted after $24 \mathrm{~h}$ and samples representing $2 \mathrm{~cm}^{2}$ of culture were assayed for luciferase activity. The mean number of light units produced by three replicate cultures and the range are displayed. were injected into the assay tube, and the light units generated over a 30-s interval were recorded by a Lumat LB 9501 luminometer (EG\&G Berthold, Nashua, NH, USA). A histochemical assay was used for $\beta$-galactosidase in fixed cells as described in detail by MacGregor et al. (16).

\section{RESULTS AND CONCLUSIONS}

A luciferase reporter gene signal of almost three orders of magnitude above background was obtained when early-passage HUVECs were transfected with DNA complexed with replication-defective adenovirus particles. Figure 1 shows the luciferase signals obtained from cytoplasmic extracts representing $2 \mathrm{~cm}^{2}$ of endothelial cell culture transfected with the standard amount of pCLuc4, $300 \mathrm{ng} / \mathrm{cm}^{2}$. An even larger signal is produced by cells of the continuous differentiated EA.hy926 line. The relatively undifferentiated A549/8 cells produce a still greater transfection signal. The variation among three replicate cultures was small for EA.hy926 and A549/8 cells, which represent clonally pure cell lines, but variation among replicate HUVEC cultures was greater as indicated in the figure. Total protein concentrations in the HUVEC lysates from replicate cultures differed from the means by $5 \%$ or less and did not correlate with differences in the reporter signals. It is noted that trypsinization to the point of monodispersion is contra-indicated for successful passage of HUVECs, so plate-to-plate variation in culture morphology or "patchiness" due to different distributions of cell aggregates might be expected, and these differences could conceivably affect the efficiency of transfection and/or expression of the transfected DNA.

The reporter signal generated was found to be linearly related to the amount of DNA transfected. Figure 2 shows the reporter signals generated by EA.hy926 cultures transfected with adenovirus complexed with varying amounts of reporter DNA. The reporter signal was proportional to the amount of DNA over multiple orders of magnitude. The signal variation among the EA.hy926 replicate cultures was small 
at all levels of DNA transfected. In HUVEC transfection experiments (data not shown), the reporter signals were also found to vary with the amount of DNA transfected. However, the signal variation among replicate HUVEC cultures was substantial at all levels of DNA transfected, and the signal-to-DNA profile differed from one HUVEC experiment to another even when consecutive early passages of the same line of HUVECs were used.

The transient expression signals achieved were similar whether repli- cation-competent or incompetent adenoviruses were used in forming the transfection complexes. This is indicated by data for $300 \mathrm{ng} / \mathrm{cm}^{2}$ shown in Figures 1 and 2. The replicationcompetent P202 adenovirus was used for the experiment in Figure 2, and the incompetent E1A/E1B-deleted P259A virus was used for the experiment in Figure 1.

The adenovirus component of the transfection complex was the major determinant of gene transfer efficiency into EA.hy926 endothelial cells.

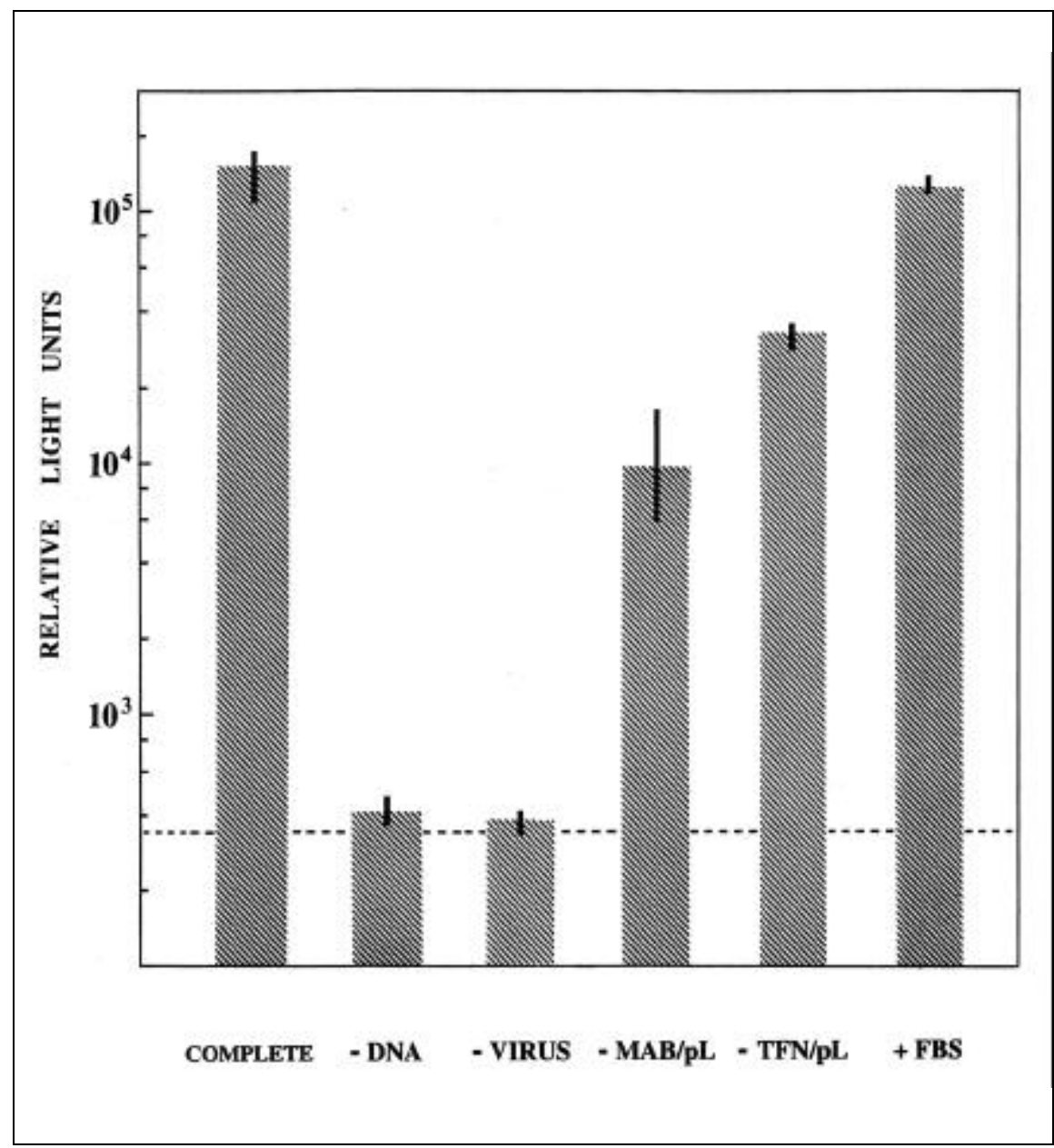

Figure 3. The dependence of transfection reporter signals obtained on various components of the transfection complex. A complete transfection complex involving pCLuc4 DNA and P202 adenovirus was prepared as described in Materials and Methods. Incomplete complexes were prepared identically except that one lacked DNA (- DNA), another lacked virus (- VIRUS), another lacked the monoclonal antibody polylysine conjugate $(-\mathrm{Mab} / \mathrm{pL})$ and another lacked the transferrin-polylysine conjugate (TFN/pL). A complete complex preparation with FBS in addition to the usual components (+ FBS) was also tested. Replicate cultures of subconfluent EA.hy926 cells were exposed to the various transfection complexes at $4^{\circ} \mathrm{C}$ for $3 \mathrm{~h}$, the unbound transfection complexes were then washed away and cultures were returned to $37^{\circ} \mathrm{C}$ with growth medium for $24 \mathrm{~h}$. The cells were then extracted, and samples representing $2 \mathrm{~cm}^{2}$ of culture were assayed for luciferase activity. The mean number of light units produced by three replicate cultures and the range are displayed. The dashed line indicates the assay background with no cellular extract.

The relative contributions of various components of the transfection complex to the efficiency of the transfection were examined by leaving out individual components when preparing the complexes as specified in Materials and Methods. In this experiment, the transfection complexes were applied to EA.hy 926 cells at $4^{\circ} \mathrm{C}$ (instead of room temperature) to delay endocytosis and recycling of receptors. After $3 \mathrm{~h}$ at $4^{\circ} \mathrm{C}$, the cultures were carefully rinsed using HEPES-buffered DMEM with $2 \%$ FBS to remove all of the transfection components not bound to the cell, complete growth medium was added, and the cultures were gradually returned to $37^{\circ} \mathrm{C}$. After $24 \mathrm{~h}$, cell extracts were prepared, and luciferase activity was assayed as usual. The reporter signals generated under these transfection conditions are shown in Figure 3. The complete transfection complex with adenovirus $\mathrm{P} 202$ resulted in a large signal (although not as large as that obtained when transfection is conducted at room temperature, which would allow recycling of receptors). When the DNA was deleted, the signal was at background levels as expected. When only the virus was deleted, the signal was also at background levels, indicat-

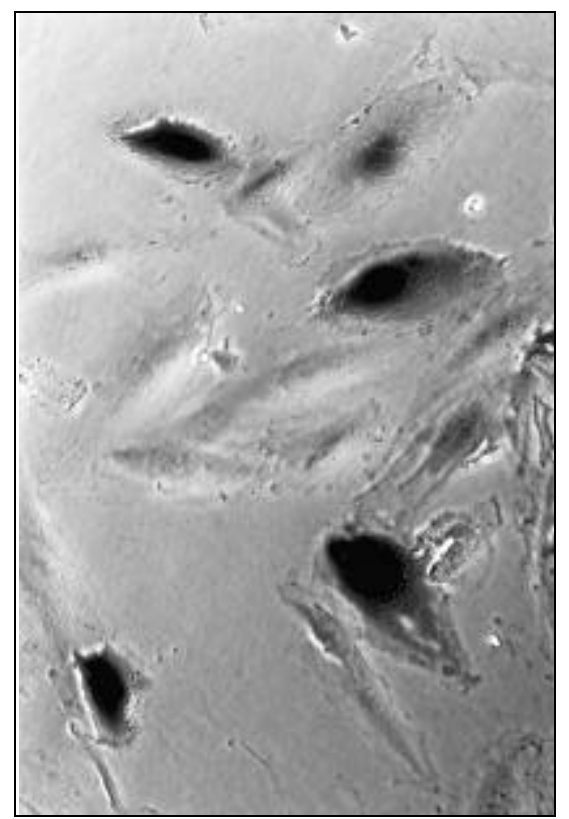

Figure 4. HUVECs transfected with pCMV $\beta$ DNA complexed with adenovirus P202 and histochemically stained for $\beta$-galactosidase activity after $24 \mathrm{~h}$. 
ing that this component is very important for transfection efficiency. When the antibody-polylysine component was deleted, only $6 \%$ of the full signal was obtained, suggesting that the physical linkage of the DNA to the virus by the antibody bridges contributes substantially to transfection efficiency. When the transferrin-polylysine component was deleted, only $20 \%$ of the full signal was obtained. This might indicate that transferrin binding sites and/or polylysine binding sites contributed to the cellular uptake of DNA, but the adenovirus component was required to obtain significant expression of the DNA-encoded reporter. When $2 \%$ FBS was present along with the transfection complex, there was no significant difference in the signal obtained, suggesting that serum components (such as transferrin) block few, if any, of the cellular receptors involved in binding the transfection complexes.

A significant fraction of endothelial cells can be transfected by adenovirus-complexed DNA. To determine what fraction of the cells are transfected by adenovirus-DNA complexes, the $\beta$-galactosidase reporter gene construct pCMV- $\beta$ was used to transfect HUVECs and EA.hy926 cells. The cells were transfected using DNA complexed with adenovirus P202 as described above, fixed with paraformaldehyde $24 \mathrm{~h}$ after transfection and histochemically stained for $\beta$ galactosidase to assess individual cells for reporter gene activity. Figure 4 shows transfected HUVECs stained for $\beta$-galactosidase. Some of the cells stained intensely, and other cells were negative. Neither cell size nor local cell density seemed to correlate with $\beta$ galactosidase staining. About $3 \%$ of the HUVECs and 4\% of EA.hy926 cells were found to be $\beta$-galactosidase-positive using the same transfection reagents. Thus, approximately the same proportion of these two cell types can be transfected by adenovirus-attached DNA, despite the fact that some HUVECs produce considerably lower levels of the extractable luciferase reporter compared to EA.hy926 cells (Figure 1). When the amount of virus was increased 5 -fold in the $\beta$-galactosidase transfection complexes, the fraction of HUVECs that expressed the reporter

Table 1. Frequency of Transfected Endothelial Cells Depends on Virus Particle Concentration

\begin{tabular}{|lccc|}
\hline Cells & $\begin{array}{c}\text { DNA } \\
\mathbf{n g} / \mathbf{c m}^{2}\end{array}$ & $\begin{array}{c}\text { P202 } \\
\text { Virus } \\
\mathbf{P} / \mathbf{c m}^{2}\end{array}$ & $\begin{array}{c}\boldsymbol{\beta} \text {-gal-positive } \\
\text { after 24 } \mathbf{~}\end{array}$ \\
\hline HUVEC & 30 & $1.2 \times 10^{9}$ & $3.3 \%$ \\
HUVEC & 30 & $6.0 \times 10^{9}$ & $20 \%$ \\
EA.hy926 & 60 & $1.2 \times 10^{9}$ & $4.1 \%$ \\
\hline
\end{tabular}

Table 2. Comparisons of Adenovirus Complexes and LIPOFECTAMINE Transfection Efficiencies

\begin{tabular}{|cccc|}
\hline & & $\begin{array}{c}\text { EA.hy926 } \\
\text { ( } \beta \text {-gal-positive cells) }\end{array}$ \\
\hline Adenovirus (P202 at & $24 \mathrm{~h}$ & $11 \%$ & $65 \%$ \\
$\left.1.2 \times 10^{9} \mathrm{P} / \mathrm{cm}^{2}\right)$ & $48 \mathrm{~h}$ & $38 \%$ & $57 \%$ \\
& $24 \mathrm{~h}$ & $0.1 \%$ & $1.5 \%$ \\
LIPOFECTAMINE & $48 \mathrm{~h}$ & $0.2 \%$ & $1.2 \%$ \\
\hline
\end{tabular}

gene also increased about 5-fold to $20 \%$ (Table 1), but considerable cytopathology was noted with the higher levels of this replication-competent virus. These data indicate that the virus concentration in the transfection complex is a limiting factor in transfection efficiency.

Adenovirus-complexed DNA transfection was more efficient than LIPOFECTAMINE transfection for two cell types tested. Transfection of EA.hy926 endothelial cells with adenovirus (P202, at $1.2 \mathrm{P} / \mathrm{cm}^{2}$ ) complexes was 100-fold more efficient than transfection with LIPOFECTAMINE used according to the manufacturer's instructions. Replicate cultures of EA.hy926 and of A549/8 cells were transfected side by side using the same concentrations of DNA and exposure times. Table 2 shows that the transfection efficiency was much greater for both cell types using adenovirus complexes.

\section{DISCUSSION}

Our data indicate that transfection of human endothelium-derived cells is strongly facilitated by complexing the DNA with adenovirus particles. Using this method, a high level of reporter gene expression is achieved, and a much larger fraction of the exposed cells can be shown to express the transgene than that reported with 5 other transfection methods that have been optimized for endothelial cells (23). By complexing the transfecting DNA with adenovirus-antibody-polylysine plus transferrin-polylysine, more than $3 \%$ of an HUVEC population were found to express the $\beta$-galactosidase reporter (Table 1), and luciferase reporter signals three orders of magnitude above background were obtained (Figure 1). Using this method, even higher transient expression signals were obtained with the well-differentiated continuous human EA.hy926 endothelial cell line that has also been found to be resistant to transfection by other commonly used methods (23). The reporter response was linearly related to the amount of DNA transfected over 5 orders of magnitude (Figure 2). This strong linear response would be very convenient for analysis of endothelium-specific gene expression.

Data in Table 1 and Figure 3 indicate that the adenovirus component contributes prominently to transfection efficiency. Virus particles can escort the complexed reporter gene by cellular receptors into endosomes, which are then disrupted in response to viral coat proteins before combining with lysosomes 
(22), allowing the DNA to enter the cytoplasm and then the nucleus. We have used polylysine conjugated to a virusspecific monoclonal antibody to link the transfecting DNA to the virus, but other methods of associating them might be more convenient $(9,19)$.

The adenoviral genome is not likely to have had a significant effect on the reporter gene expression in our experiments for several reasons. The viral DNA is not directly linked to the reporter DNA, ruling out any cis effect. An adenovirus strain deleted in the E1A/E1B genes (which must be expressed before the other viral genes) was approximately as effective in mediating transfection of EA.hy926 cells as was an adenovirus strain with all genes intact, as shown in Figures 1 and 2. Thus, trans effects of adenovirus gene products on expression of the reporter gene are not indicated. Functions of the adenovirus coat proteins in the transfection complex are likely to be responsible for the major effect of viral particles on the efficiency of the transfection method.

Using adenovirus-complexed DNA for transfection, the frequencies of transfected cells were similar for HUVEC and EA.hy926, but the two cell types produced significantly different levels of luciferase reporter signals in their lysates. This difference could indicate that the number of reporter genes that reach the nucleus differs for the two cell types and/or that the capacity to transcribe and translate the reporter gene differs for the two cell types. Because EA.hy926 cells replicate faster than HUVEC cells under common culture conditions, the former might have a greater overall capacity for transcription/translation than the latter.

There is considerable variation in the response of replicate HUVEC cultures to the same transfection complex but little variation in replicate EA. hy926 cultures and replicate A549/8 cultures. The substantial variability in response of replicate HUVEC cultures might be related to the distribution of cell aggregates during plating of these cells. A greater fraction of the cells in some plates might have been in confluent configurations, even though protein assays indicate that the same total amount of cellular material was deliv- ered to each plate. Cell density is known to affect transfection efficiency for many cell types.

Efficient transfection methods for endothelial cells are important for analyses of tissue-specific promoters by transient expression experiments. There is a great deal to be learned about the regulation of genes that are differentially expressed in endothelial cells, including genes involved in hemostasis, blood pressure regulation, the inflammatory response, wound healing and angiogenesis. The endothelium has also been considered a good potential target for gene therapy because secreted gene products can be introduced directly into the circulation. Transfection efficiency will be important for such applications whether transfection is accomplished in vivo or in culture. In vivo transfection of endothelial cells would have to occur before the transfecting complexes were removed from the circulation by various physiological mechanisms, and transfection in culture would involve a very limited number of homologous endothelial cells. Others have demonstrated that a gene incorporated into the adenovirus genome can be efficiently introduced into endothelial cells in culture and into umbilical vein endothelial cells in situ (13). However, there are several advantages to transfection by adenovirus-DNA complexes compared to infection by an adenovirus with an incorporated transgene. Transfection by adenovirus-polylysine-DNA complexes allows very large DNA sequences to be transferred. Potential $c$ is effects of the viral genome on the transferred gene are avoided. Genetic effects of adenovirus on the recipient cells (or organism) can be minimized by using virus with mutationally and/or physically (UV) inactivated viral genomes. There are additional important practical advantages to adenovirus-DNA complex transfection over adenovirus infection for analyses of endothelial cellspecific promoters. DNA promoter/ reporter constructs of any design can be used. Co-transfection with control constructs, with competitive regulatory sequences or with genes for trans-acting factors can be readily accommodated. Thus, efficient transfection of endothelial cells using adenovirus-DNA complexes represents significant 
advantages for tissue-specific promoter analyses as well as potential for gene therapy applications.

\section{ACKNOWLEDGMENTS}

This work was supported in part by National Institutes of Health Grants Nos. HL45100 and HL55452.

\section{REFERENCES}

1.Carney, D.N., C.J. Edgell, A.F. Gazdar and J.D. Minna. 1979. Suppression of malignancy in human lung cancer (A549/8) x mouse fibroblast (3T3-4E) somatic cell hybrids. J. Natl. Cancer Inst. 62:411-415.

2.Cotten, M., E. Wagner and M.L. Birnstiel. 1993. Receptor mediated transport of DNA into eucaryotic cells. Methods Enzymol.
217:618-644.

3.Cotten, M., E. Wagner, K. Zatloukal, S. Phillips, D.T. Curiel and M.L. Birnstiel. 1992. High-efficiency receptor-mediated delivery of small and large (48 kilobase) gene constructs using the endosome-disruption activity of defective or chemically inactivated adenovirus particles. Proc. Natl. Acad. Sci. USA 89:6094-6098.

4.Curiel, D.T., S. Agarwal, E. Wagner and M. Cotten. 1991. Adenovirus enhancement of transferrin-polylysine-mediated gene delivery. Proc. Natl. Acad. Sci. USA 88:8850-8854.

5.Curiel, D.T, E. Wagner, M. Cotten, M.L. Birnstiel, S. Agarwal, C.M. Li, S. Loechel and P.C. Hu. 1992. High-efficiency gene transfer mediated by adenovirus coupled to DNA-polylysine complexes. Hum. Gene Ther. 3:147-154.

6.de Wet, J.R., K.V. Wood, M. DeLuca, D.R. Helinski and S. Subramani. 1987. Firefly luciferase gene: structure and expression in mammalian cells. Mol. Cell. Biol. 7:725-737.

7.Edgell, C.J.S., C.C. McDonald and J.B. Graham. 1983. Permanent cell line expressing human factor VIII-related antigen established by hybridization. Proc. Natl. Acad. Sci. USA 80:3734-3737.

8.Eglitis, M.A. and W.F. Anderson. 1988 Retroviral vectors for introduction of genes into mammalian cells. BioTechniques 6:608 614.

9.Forsayeth, J.R. and P.D. Garcia. 1994. Adenovirus-mediated transfection of cultured cells. BioTechniques 17:354-359.

10.Gimbrone, M.A. 1976. Culture of vascular endothelium. Prog. Hemost. Thromb. 3:1-28.

11.Ginsburg, D. and E.J.W. Bowie. 1992. Molecular genetics of von Willebrand disease. Blood 79:2507-2519.

12.Jaffe, E.A., R.L. Nachman, C.G. Becker and C.R. Minick. 1973. Culture of human endothelial cells derived from umbilical veins. J. Clin. Invest. 52:2745-2756.

13.Lemarchand, P., H.A. Jaffe, C. Danel, M.C. Cid, H.K. Kleinman, L.D. Stratford-Perricaudet, M. Perricaudet, A. Pavirani, J.P. Lecocq and R.G. Crystal. 1992. Adenovirusmediated transfer of a recombinant human $\alpha_{1-}$ antitrypsin cDNA to human endothelial cells. Proc. Natl. Acad. Sci. USA 89:6482-6486.

14.Lieber, M., B. Smith, A. Szakal, W. NelsonRees and G. Todaro. 1976. A continuous tumor-cell line from a human lung carcinoma with properties of type II alveolar epithelial cells. Int. J. Cancer 17:62-70.

15.MacGregor, G.R. and C.T. Caskey. 1989. Construction of plasmids that express $E$. coli $\beta$-galactosidase in mammalian cells. Nucleic Acids Res. 17:2365.

16.MacGregor, G.R., G.P. Nolan, S. Fiering, M. Roederer and L.A. Herzenberg. 1989. Use of Escherichia coli lacZ ( $\beta$-galactosidase) as a reporter gene. Methods Mol. Biol. 7:217236.

17.Nathwani, A.C., K.M. Gale, K.D. Pemberton, D.C. Crossman, E.G.D. Tuddenham and J.H. McVey. 1994. Efficient gene transfer into human umbilical vein endothelial cells allows functional analysis of the human tissue factor gene promoter. Br. J. Haematol. 88:122128.
18.Plank, C., K. Zatloukal, M. Cotten, K. Mechtler and E. Wagner. 1992. Gene transfer into hepatocytes using asialoglycoprotein receptor mediated endocytosis of DNA complexed with an artificial tetra-antennary galactose ligand. Bioconjug. Chem. 3:533-539.

19.Raja-Walia, R., J. Webber, J. Naftilan, G.D. Chapman and A.J. Naftilan. 1995. Enhancement of liposome-mediated gene transfer into vascular tissue by replication deficient adenovirus. Gene Ther. 2:521-530.

20.Rieber, A.J., H.S. Marr, M.B. Comer and C.J.S. Edgell. 1993. Extent of differentiated gene expression in the human endotheliumderived EA.hy926 cell line. Thromb. Haemost. 69:476-480.

21.Schwachtgen, J.-L., V. Ferreira, D. Meyer and D. Kerbiriou-Nabias. 1994. Optimization of the transfection of human endothelial cells by electroporation. BioTechniques 17:882-887.

22.Seth, P., D. Fitzgerald, M. Willingham and I. Pastan. 1986. Pathway of adenovirus entry into cells: some new observation on an old problem, p. 191-195. In R.L. Crowell and K. Lonberg-Holm (Eds.), Virus Attachment and Entry into Cells. Am. Soc. Microbiol., Washington DC.

23.Teifel, M., L.T. Heine, S. Milbredt and P. Friedl. 1997. Optimization of transfection of human endothelial cells. Endothelium 5:2135

24.Wagner, E., K. Zatloukal, M. Cotten, H. Kirlappos, K. Mechtler, D.T. Curiel and M.L. Birnstiel. 1992. Coupling of adenovirus to transferrin-polylysine/DNA complexes greatly enhances receptor-mediated gene delivery and expression of transfected genes. Proc. Natl. Acad. Sci. USA 89:6099-6103.

25.Wagner, E., M. Zenke, M. Cotten, H. Beug and M.L. Birnstiel. 1990. Transferrin-polycation conjugates as carriers for DNA uptake into cells. Proc. Natl. Acad. Sci. USA 87:3410-3414.

26.Wilson, D.B., D.M. Dorfman and S.H. Orkin. 1992. A nonerythroid GATA-binding protein is required for function of the human preproendothelin-1 promoter in endothelial cells. Mol. Cell. Biol. 10:4854-4862.

27.Wilson, J.M., L.K. Birinyi, R.N. Salomon, P. Libby, A.D. Callow and R.C. Mulligan. 1989. Implantation of vascular grafts lined with genetically modified endothelial cells. Science 244:1344-1346.

Received 15 December 1997; accepted 13 March 1998.

\section{Address correspondence to:}

Dr. Cora-Jean S. Edgell

Pathology Department

University of North Carolina

Chapel Hill, NC 27599-7525, USA

Internet:edgellcj@med.unc.edu 